\title{
A study of dog bites among children in the rural area of Goa, India
}

\author{
Shefalee Pai Vernekar ${ }^{1}$, Archana Desai ${ }^{2, *}$ \\ ${ }^{1}$ Post Graduate Student, ${ }^{2}$ Assistant Lecturer, Dept. of Preventive and Social Medicine, Goa Medical College, Goa, India
}

*Corresponding Author:

Email: archanadesai205@gmail.com

\begin{abstract}
Objective: 1. To study the prevalence of dog bites in children; 2. To study knowledge and practices followed regarding prevention and control of rabies among caretakers.

Materials and Methods: Study Design: Cross sectional study; Study Participants: Children below 16 years of age; Study Instrument: A predesigned questionnaire was used to ask questions to parents or caretakers of children.

Ethical Considerations: Ethical approval was obtained from Institutional Ethics Committee.

Statistical Analysis: Data was entered in excel and analysed using SPSS version 22. Frequencies, $\mathrm{X}^{2}$ tests and odds ratios were calculated.

Results: The incidence of dog bites in children was $3.36 \%$. Most of the bites were in children between $6-10$ years $(2.4 \%)$ and among males $(2.1 \%)$. Almost $55.6 \%$ of the bites were unprovoked. Most common site was lower limbs $(66.7 \%) .66 .6 \%$ of the victims received anti rabies vaccine (ARV). Out of those who received ARV, only $66.7 \%$ received all doses completely. Knowledge of rabies and ARV was present in $83 \%$ and $74 \%$ of the parents respectively.

Conclusion: Most of the bites happen in and around the house, which can be easily prevented. Even though free health services are so easily accessible, services are not availed. Health education regarding prevention of dog bites, correct methods of local bite management and compliance of ARV treatment is needed.
\end{abstract}

Keywords: Dog bites, Children, Rural, Goa.

\section{Introduction}

Rabies is a viral disease which occurs in more than 150 countries and territories. It is an almost always fatal infectious disease and a major public health problem. It is one of the neglected tropical diseases that predominantly affect poor and vulnerable populations who live in remote rural locations. ${ }^{1}$ Dogs are the main source of human rabies deaths, contributing up to $99 \%$ of all rabies transmissions to humans.

Studies have shown that when compared to adults, children are at a higher risk of dog bites and contracting rabies. $40 \%$ of people bitten by suspect rabid animals are children under 15 years of age. This is explained by children possessing lower awareness, lesser knowledge in safe behavior around dogs, higher vulnerability due to lower physical strength and smaller size. ${ }^{2}$

An estimated 59,000 people die from rabies across the world each year, with around $90 \%$ of these deaths occurring among children living in rural areas in Africa and Asia. In India alone, estimates range between 18000 to 20000 human deaths from rabies each year. Many of these deaths are children, often dying outside of medical facilities. ${ }^{3}$

As many as 73,180 dog bites cases have been reported in Goa since the last 4.5 years according to the Directorate of Health Services, Goa. ${ }^{4}$

Awareness about rabies is poor, especially among the rural population. In spite of free vaccines and immunoglobulin available at health centres, people often do not take proper prophylaxis. Although fatal, it can be effectively prevented. WHO recommends that proper wound management and post exposure prophylaxis is an effective way for rabies prevention.
Hence, the present study was carried out with the following aims and objectives:

To study the prevalence of dog bites in children

To study knowledge and practices followed regarding prevention and control of rabies among caretakers.

\section{Materials and Methods}

Study Design: This study was a community based cross sectional study

Study Area and Setting: Field practice area of Rural Health and Training Centre (RHTC) Mandur, Goa, India. There are four villages under the field practice area of Rural Health Centre of Mandur. Two out of these four villages were randomly selected.

Sample Size and Sampling: All children 16 years of age or below were selected. Total population of children below 16 years of age was 554. The sample size of the study was 536 as 18 children could not be contacted even after 3 visits.

Data Collection Method: A house to house survey was done in the two villages for a period of one month. Children under 16 years were identified. A predesigned questionnaire was used to ask questions to parents or caretakers of children. The information on socio demographic details, history of dog bite in children in the preceding 12 months, details about dog bite and treatment, knowledge about prevention and control of rabies among the parents was obtained.

Informed consent from parents of children was taken prior to administering the questionnaire. Ethical approval was taken from institutional ethics committee of Goa Medical College. 
Data Analysis: Data was analyzed using SPSS (version 22 software). The prevalence of dog bites in children was estimated. Frequencies, $\mathrm{X}^{2}$ tests and odds ratios were calculated. A p value of 0.05 was considered significant.

\section{Results}

The incidence of dog bites in children was $3.36 \%$. Out of 536 children, 18 gave history of dog bite in the preceding 12 months. Majority of the children (36.2\%) were less than 5 years of age and majority (55.6\%) were males. Most of the bites were in children between $6-10$ years $(2.4 \%)$ and among males $(2.1 \%)$. (Refer Table 1)

12 out of 18 children $(66.6 \%)$ were bitten in and around the house or on the street and most of them were by stray dogs $(61.1 \%)$. Almost $55.6 \%$ of the bites were unprovoked. Most common site was lower limbs (66.7\%). (Refer Table 2)
Following the dog bite, only $38.9 \%$ children had washed their wound with soap and water. Only $55.6 \%$ of the victims were brought to the health centre and out of those brought only $42.8 \%$ were brought immediately. $33.3 \%$ received some form of home / quack remedy. Out of those who received anti rabies vaccine (ARV), only $66.7 \%$ received all doses completely. (Refer Table 3)

The parents and caretakers were asked about knowledge and practices in regards to rabies prevention. It was seen that $83 \%$ of the parents knew about mode of rabies transmission and $74 \%$ knew about the anti rabies vaccine. The knowledge of wound washing as the first aid measure and the need to visit the health centre to seek treatment following a dog bite was present among $70 \%$ and $88 \%$ of the cases respectively. However, only $38 \%$ of the parents said that the dog should be observed for 10 days following dog bite for development of symptoms and signs suggestive of rabies.

Table 1: Socio demographic characteristics of participants

\begin{tabular}{|c|c|c|c|c|c|}
\hline \multicolumn{4}{|l|}{ Dog bites } & \multirow{2}{*}{$\begin{array}{c}\text { Odds Ratio } \\
\text { (95\% CI) }\end{array}$} & \multirow{2}{*}{$\begin{array}{c}\text { Test of } \\
\text { significance }\end{array}$} \\
\hline & $\begin{array}{c}\text { Yes } \\
\mathbf{N}(\%)\end{array}$ & $\begin{array}{c}\text { No } \\
\mathbf{N}(\%)\end{array}$ & $\begin{array}{l}\text { Total } \\
\mathbf{N}(\%)\end{array}$ & & \\
\hline \multicolumn{5}{|c|}{ Age (years) } & \multirow{4}{*}{$\begin{array}{l}X^{2}=15.5 \\
p=0.0004\end{array}$} \\
\hline $0-5$ & $\begin{array}{c}2 \\
(0.4)\end{array}$ & $\begin{array}{c}192 \\
(35.8)\end{array}$ & $\begin{array}{c}194 \\
(36.2)\end{array}$ & 1(ref) & \\
\hline $6-10$ & $\begin{array}{c}13 \\
(2.4)\end{array}$ & $\begin{array}{c}150 \\
(28.0)\end{array}$ & $\begin{array}{c}163 \\
(30.4)\end{array}$ & 8.32 & \\
\hline $11-16$ & $\begin{array}{c}3 \\
(0.6) \\
\end{array}$ & $\begin{array}{c}176 \\
(32.8)\end{array}$ & $\begin{array}{c}179 \\
(33.4)\end{array}$ & 1.64 & \\
\hline \multicolumn{5}{|c|}{ Sex } & \multirow{3}{*}{$\begin{array}{l}X^{2}=0.23 \\
p=0.6319\end{array}$} \\
\hline Male & $\begin{array}{c}11 \\
(2.1)\end{array}$ & $\begin{array}{c}287 \\
(53.5)\end{array}$ & $\begin{array}{c}298 \\
(55.6)\end{array}$ & 1.26 & \\
\hline Female & $\begin{array}{c}7 \\
(1.3) \\
\end{array}$ & $\begin{array}{c}231 \\
(43.1) \\
\end{array}$ & $\begin{array}{c}238 \\
(44.4) \\
\end{array}$ & 1(ref) & \\
\hline $\begin{array}{l}\text { Total } \\
\text { N }(\%)\end{array}$ & $\begin{array}{c}18 \\
(3.4)\end{array}$ & $\begin{array}{c}518 \\
(96.6)\end{array}$ & $\begin{array}{c}536 \\
(100)\end{array}$ & & \\
\hline
\end{tabular}

$\mathrm{p}<0.05$ is considered significant

Table 2: Characteristics of dog bites

\begin{tabular}{|c|c|c|c|}
\hline Variable & Male N (\%) & $\begin{array}{c}\text { Female } \\
\mathbf{N}(\%)\end{array}$ & $\begin{array}{c}\text { Total } \\
\mathbf{N}(\%)\end{array}$ \\
\hline \multicolumn{4}{|l|}{ Place of bite } \\
\hline House/street & 7(38.9) & $5(27.8)$ & $12(66.7)$ \\
\hline Near school & $4(22.2)$ & $2(11.1)$ & $6(33.3)$ \\
\hline \multicolumn{4}{|l|}{ Type of dog } \\
\hline Pet & $5(27.8)$ & $2(11.1)$ & $7(38.9)$ \\
\hline Stray & $6(33.3)$ & $5(27.8)$ & 11(61.1) \\
\hline \multicolumn{4}{|c|}{ Nature of bite } \\
\hline Provoked & $5(27.8)$ & $3(16.7)$ & $8(44.4)$ \\
\hline Unprovoked & $6(33.3)$ & $4(22.2)$ & $10(55.6)$ \\
\hline \multicolumn{4}{|c|}{ Site of bite } \\
\hline Lower limb & $5(27.8)$ & $7(38.9)$ & $12(66.7)$ \\
\hline Upper limb & $3(16.6)$ & $0(0)$ & $3(16.7)$ \\
\hline
\end{tabular}




\begin{tabular}{|l|c|c|c|}
\hline Chest/abdomen/back & $2(11.1)$ & $0(0)$ & $2(11.1)$ \\
\hline Head/face/neck & $1(05.6)$ & $0(0)$ & $1(5.6)$ \\
\hline
\end{tabular}

Table 3: Management practices following dog bite

\begin{tabular}{|c|c|c|c|}
\hline Variable & $\begin{array}{c}\text { Male } \\
\mathbf{N}(\%)\end{array}$ & $\begin{array}{c}\text { Female } \\
\mathbf{N}(\%)\end{array}$ & Total N (\%) \\
\hline \multicolumn{4}{|l|}{ Place of treatment } \\
\hline RHTC & $6(33.3)$ & $4(22.2)$ & $10(55.6)$ \\
\hline Private & $2(11.1)$ & $2(11.1)$ & $4(22.2)$ \\
\hline Home/quack/other & $3(16.7)$ & $1(5.60)$ & $4(22.2)$ \\
\hline \multicolumn{4}{|c|}{ Brought to doctor immediately } \\
\hline Yes & $5(35.7)$ & $1(7.10)$ & $6(42.8)$ \\
\hline No & $3(21.5)$ & $5(35.7)$ & $8(57.2)$ \\
\hline \multicolumn{4}{|l|}{ Treatment received } \\
\hline ARV/ ARV + Other & $8(44.4)$ & $4(22.2)$ & $12(66.6)$ \\
\hline Quack/home remedy/None & $3(16.7)$ & $3(16.7)$ & $6(33.3)$ \\
\hline \multicolumn{4}{|l|}{ ARV all doses completed } \\
\hline Yes & $5(41.7)$ & $3(25)$ & $8(66.7)$ \\
\hline No & $3(25.0)$ & $1(8.3)$ & $4(33.3)$ \\
\hline \multicolumn{4}{|c|}{ Washed with soap and water immediately } \\
\hline Yes & $3(16.7)$ & $4(22.2)$ & $7(38.9)$ \\
\hline No & $8(44.4)$ & $3(16.7)$ & $11(61.1)$ \\
\hline
\end{tabular}

Table 4: Knowledge and practices in regards to prevention of rabies

\begin{tabular}{|l|c|c|}
\hline Variable & Present (\%) & Absent (\%) \\
\hline Knowledge of rabies transmission & $446(83.2)$ & $90(16.8)$ \\
\hline Knowledge of treatment following rabies(ARV) & $399(74.4)$ & $137(25.6)$ \\
\hline First aid measure (wound washing) & $377(70.3)$ & $159(29.7)$ \\
\hline Treatment centre following dog bite & $471(87.9)$ & $65(12.1)$ \\
\hline Observation of dog & $203(37.87)$ & $333(62.1)$ \\
\hline
\end{tabular}

\section{Discussion}

The present community based study covered a population of 536 children. This study shows a higher male predominance in dog bites cases which is similar to studies reported by Venkatesan $\mathrm{M}$ et al, ${ }^{5}$ Kale et al, ${ }^{7}$ Van et al. ${ }^{8}$ In the present study highest number of cases were among $6-10$ years old similar to that reported by Venkatesan et al..$^{5}$ This is probably due to natural behavior of young boys to play outside and this reflects the need of constant supervision by parents or caretakers. Also, children can be taught to behave in a safe manner around dogs i.e. avoid provoking dogs by pelting stones etc. Number of unprovoked bites were more $(55.6 \%)$, as also reported by Behera et al, ${ }^{10}$ Venkatesan $\mathrm{M}^{5}$ and Icchapujani et al. Lower limb is the most common site as reported in other studies. ${ }^{7,9}$ Wound washing was done only in $38.9 \%$ victims which is comparable to the nationwide study by Sudharshan. ${ }^{12}$ Only 55.6\% visited RHTC in spite of it being so close to the residence and providing 24 hours services. $22.2 \%$ of patients reported to have used some home remedy in the form of irritants like turmeric powder, some quack treatment in the form of some oral tablets or no remedy at all. Out of those who received ARV, 33.3\% did not complete their doses even though they were available free of cost at the close by health facility. This may be due to lack of awareness about importance of ARV in prevention of rabies. This indicates that even though the health services and free treatment is available people are not availing, probably due to lack of health education.

The knowledge regarding prevention of rabies was also found to be poor. $82 \%$ of parents/caretakers answered correctly about the disease and its transmission which is much higher than that reported by Kumar S et al $(56.9 \%) .{ }^{13}$ Around $30 \%$ of them did not feel there was a need to wash the wound with soap and water following dog bite which is better than that reported by other studies. ${ }^{13} 25.6 \%$ of them were not aware of what treatment they have to seek following a dog bite.

\section{Conclusion}

The prevalence of dog bites in children is high particularly among $6-10$ years of age and more common in males. Most of the bites can be easily prevented. Parental/ caretakers supervision while playing outside and development of dog bite prevention program as a part of school health education may help children to deal with such a situation. Even though free health services are so easily accessible, services are not availed probably due to lack of awareness among 
people regarding the disease and its prevention. Health education regarding prevention of dog bites and rabies is needed.

Contribution of authors: Dr. Shefalee Pai Vernekar and Dr. Archana Desai were involved in conception, design, drafting, data analysis, interpretation and critical evaluation of the article and final approval of the manuscript.

Disclosure: There is no conflict of interest for any of the authors.

Funding: No funding was received for the study

\section{Conflicts of Interest: Nil}

\section{References}

1. World Health Organisation. "Rabies". WHO. 2017. Available at: www.who.int/mediacentre/factsheets/fs099/en/. Accessed: 20/06/2017.

2. Seligsohn D. "Dog bite incidence and increased risk factors". [dissertation on Internet]. [Sweden]: Swedish University of Agricultural Science. ; 2014. Available at: https://stud.epsilon.slu.se. Accessed: 20/06/2017.

3. WHO. "Eliminating rabies in India through awareness, treatment and vaccination". WHO. 2016. Available at: www.who.int/features/2016/eliminating-rabies-india/en/. Accessed: 20/06/2017.
4. "Goa sees substantial rise in dog bite cases". Directorate of Health Services, Goa.

5. Venkatesan M, Dongre AR, Kalaiselvan G. “A

Community based cross sectional study of dog bites in children in a rural district of Tamil Nadu". Int J Med Sci Public Health 2017;6:109-112.

6. Venkatesan M, Dongre AR, Kalaiselvan G. “An epidemiological study of animal bites and evenomings in a rural district of Tamil Nadu". Online J Health Allied Scs. 2014;13(4):4.

7. Kale KM, Wadhva SK, Aswar NR, Vasudev ND. "Dog bites in children". Indian J Comm Med 2006;31(1):24-5.

8. Van AB, Dwyer JP, Naido S. "Dog bites to head, neck and facein children". South Afr J Epidemiol Infect 2010;25(1);36-8.

9. Osaghae DO. "Animal and Human bites in children". West AfrJMed 2011;30(6):421-4.

10. Behera TR, Satapathy DM, Tripathiy RM, Sahu A "Profile of animal bite cases attending the ARC of M.K.C.G. Medical College, Behrampur (Orissa)". APCRI $J$ 2008; 9(2).

11. Ichhpujani RL et al. "Epidemiology of animal bites and rabies cases in India". A multicentric study. J Commun Dis 2008;40(1);27-36.

12. Sudharshan MK. "Assessing burden of rabies in India". WHO sponsored national multi-centric rabies survey (May 2004). APCRI J 2004;6:44-5.

13. Kumar $\mathrm{S}$ et al. "A study on knowledge of animal bite victims regarding animal bite and rabies attending tertiary care hospital of Rewa City, Madhya Pradesh". Int J Med Sci Public Health 2016;5:10005-9. 